\title{
UMA EXPERIÊNCIA DE FORMAÇÃO CONTINUADA DE PROFESSORES DE ESCOLAS PÚBLICAS CEARENSES POR MEIO DO MOODLE
}

\author{
Jefrei Almeida Rocha ${ }^{1,2}$, José De SOUSA BREVEs Filho ${ }^{1}$, \\ MARCos José NeGreiros GOMES ${ }^{3}$ \\ ${ }^{1}$ Instituto Federal de Educação, Ciência e Tecnologia do Ceará (IFCE) \\ ${ }^{2}$ Secretaria da Educação do Ceará \\ ${ }^{3}$ Universidade Estadual do Ceará (UECE) \\ <jefrei_rocha@hotmail.com>. <jsbreves@uol.com.br>, <josenegreiros@hotmail.com>
}

DOI: $10.21439 /$ conexoes.v11i2.1088

\begin{abstract}
Resumo. O uso das tecnologias no ambiente escolar tem motivado diversas pesquisas em todo o mundo. No Brasil, os Ambientes Virtuais de Aprendizagem (AVA) têm ganhado espaço como ferramenta educativa. No entanto, os benefícios desse uso vão além de simplesmente repassar um conteúdo de maneira mais atraente. A interação promovida, os processos cognitivos desencadeados e a construção do conhecimento mediante o uso das ferramentas do AVA promovem a aprendizagem dos discentes e uma experiência formativa para os docentes. Em 2013, realizou-se uma pesquisa utilizando o AVA "Afiando Palavras" com alunos e professores de escolas públicas da rede estadual de educação do Ceará. Essa pesquisa oportunizou aos alunos a utilização de um AVA com proposta pedagógica própria para o ensino da leitura, e aos professores uma formação tendo pautada em sua prática docente e no uso da tecnologia, a partir de temas e necessidades de suas salas de aula.
\end{abstract}

Palavras-chaves: Ambiente Virtual de Aprendizagem; Formação docente continuada; Formação autoreflexiva de professores.

\begin{abstract}
The use of technology in schools has prompted numerous studies in the world. In Brazil, the Virtual Learning Environme nt (EVA) have gained ground as an educational tool. However, the benefits of such use are beyond just having a content more attractive. The promoted interaction, caused cognitive processes and the construction of knowledge through the use of tools AVA promote student learning and a learning experience for teachers. In 2013, a survey was conducted using the AVA "Sharpening words" with students and teachers of public schools of the state of Ceará education. This survey provided an opportunity to the students to use a VLE with its own pedagogical approach to teaching reading, and teachers training having guided in their teaching practice and use of technology, from subjects and their classrooms needs.
\end{abstract}

Keywords: virtual learning environment, continued formation of teachers, Self-reflective teacher training.

\section{INTRODUÇÃO}

Muito se tem discutido a respeito da melhoria da qualidade da educação em nosso país. Essa melhoria passa pela formação de professores, sendo apontados dois eixos para investimentos e pesquisas: os processos formativos iniciais e os processos de formação continuada. Esses dois eixos se completam e delimitam momentos diferentes da atuação docente, no entanto, é preciso desenvolver uma abordagem diferenciada para cada um dos referidos momentos, com metodologias e estratégias diferentes.

Na perspectiva de analisar formação continuada de professores baseadas em novas metodologias e estratégia de formação, esse artigo aborda algumas temáticas 

MOODLE

surgidas ao longo da pesquisa de Mestrado em Computação Aplicada da Universidade Estadual do Ceará que foi desenvolvida no ano de 2013, com a utilização do Ambiente Virtual de Aprendizagem (AVA) "Afiando Palavras", e que busca desenvolver o ensino da leitura, por meio de uma sequência didática própria. Os autores desenvolveram a pesquisa na capital cearense com a participação de escolas da rede pública estadual.

Somados aos esclarecimentos sobre as etapas da proposta pedagógica e sobre os sujeitos da pesquisa, pontuaremos algumas questões ligadas à formação continuada de professores que julgamos pertinente e que foram vislumbradas ao longo do desenvolvimento da pesquisa.

Inicialmente, o que nos motivou a realização da pesquisa foi o déficit na proficiência leitora dos alunos da rede pública estadual, que é avaliada de duas formas: nacionalmente, por meio do Sistema de Avaliação da Educação Básica (Saeb), denominado atualmente Prova Brasil; ou regionalmente, por meio de exames realizados pelas secretarias estaduais de educação. No Ceará, o Sistema Permanente de Avaliação da Educação Básica do Ceará (SPAECE) é realizado desde 1992. E posteriormente, a busca de promover o prazer pela leitura e melhorar a proficiência leitora dos alunos.

No entanto, acreditamos que a realização de pesquisas junto com os professores, oportunizando uma formação continuada na própria escola, levando-os a refletirem sobre sua prática pedagógica, mediante a construção de seu saber, possa contribuir, significativamente, com a diminuição dos problemas de ensinoaprendizagem.

A pesquisa foi desenvolvida em cinco etapas: i. revisão bibliográfica sobre o ensino da leitura, o percurso da construção de sentido do texto e sobre estratégias de leitura; ii. elaboração de uma proposta metodológica com sequências didáticas; iii. instalação do $M o$ dular Object-Oriented Dynamic Learning Environment (Ambiente de Aprendizagem Dinâmico Modular Orientado a Objeto - MOODLE) em um servidor e criação do ambiente "Afiando Palavras"; iv. utilização do ambiente com professores e alunos e; v. aplicação de um questionário com os sujeitos da pesquisa, seguida pela tabulação das respostas.

No primeiro momento, neste artigo, serão expostos alguns pressupostos citados por autores de relevância internacional para a compreensão sobre o trabalho docente e a formação de professores, como Nóvoa (1991), Tardif (2012), Pimenta (2013), Bourdieu e Foster (1999), Therrien e Loiola (2001). A partir disso, destacaremos alguns aspectos pertinentes para o enten- dimento da formação auto-reflexiva dos professores.

No segundo momento, serão esclarecidos os processos de criação do "Afiando Palavras", sua concepção estrutural e suas principais funcionalidades. Mediante esses esclarecimentos, será descrita a proposta pedagógica do ambiente, demonstrando a estrutura das sequências didáticas voltadas para o ensino da leitura no AVA.

Finalizada essa parte, uma nova seção dará conta do desenvolvimento da pesquisa nas escolas, do processo de escolha dos participantes, do uso do ambiente com professores e alunos, da aplicação dos questionários e de dados relevantes coletados junto aos sujeitos participantes.

Ao final desse artigo, ressaltaremos os benefícios do uso do "Afiando Palavras" para os processos de ensino e de aprendizagem, bem como para a formação dos professores, bem como uma reflexão acerca do modelo de formação de professores em exercício que julgamos mais coerente com a realidade atual, concluindo com uma proposta para pesquisas futuras.

\section{FUNDAMENTAÇÃO TEÓRICA}

Alvo de diversos estudos e teorias, a formação de professores, de acordo com síntese apresentada por Nóvoa (1991), transita entre modelos estruturantes e modelos construtivistas. Podendo-se entender os modelos estruturantes a partir da lógica da racionalidade técnicocientífica. Por outro lado, os modelos construtivistas lançam mão de uma reflexão contextualizada, tendo como objetivo regular as práticas e o processo de trabalho de maneira permanente. Sob essa perspectiva, as estratégias de formação continuada devem ser "necessariamente híbridas, apelando segundo uma coerência própria e contextualizada a diferentes contributos teóricos metodológicos" (NÓVOA, 1991).

Ao desenvolver uma estratégia de formação inicialmente, faz-se necessário compreender a estruturação e a construção do conhecimento do professor. Para Tardif (2012), o saber docente é plural, resultando de um amálgama, até certo ponto coerente, de saberes oriundos da formação profissional e de saberes disciplinares, curriculares e experienciais. Aprofundando a discussão sobre esses saberes, o autor usa a expressão "saberes experienciais" e esclarece que:

Pode-se chamar de saberes experienciais o conjunto de saberes atualizados, adquiridos e necessários no âmbito da prática da profissão docente e que não provêm das instituições de formação e nem dos currículos. (...) São saberes práticos (e não da prática: eles não se 
sobrepõem à prática para melhor conhecê-la, mas se integram a ela e dela são partes constituintes enquanto prática docente (TARDIF, 2012, p. 48).

Pimenta (2013) destaca a necessidade de uma postura reflexiva dos docentes na execução de suas atividades cotidianas:

(...) as transformações das práticas docentes só se efetivam na medida em que o professor amplia sua consciência sobre a própria prática. O alargamento da consciência, por sua vez, se dá pela reflexão que o professor realiza na ação. Em suas atividades cotidianas, o professor toma decisões diante das situações concretas com as quais se depara.(PIMENTA 2013, p. 23)

Nóvoa (1991) corrobora com essa ideia, reforçando que a formação continuada de professores, deve pautarse no saber e na prática docentes, atribuindo à escola o papel de local de referência:

A formação continuada deve estar articulada com desempenho profissional dos professores, tomando as escolas como lugares de referência. Trata-se de um objetivo que só adquire credibilidade se os programas de formação se estruturarem em torno de problemas e de projetos de ação e não em torno de conteúdos acadêmicos.(NÓVOA, 1991, p. 30)

Diante disso, entendemos que as ações de formação devem fomentar a reflexão do professor sobre seu saber-fazer, visando à aquisição de novos conhecimentos, desenvolvendo os predicados para vencer os obstáculos, os imponderáveis e os fatos condicionantes que fazem parte do exercício do magistério. Sendo isso possível, à medida que os docentes desenvolvem o habitus, definido por Tardif (2012) como certas disposições adquiridas na e pela prática docente. Para Bourdieu e Foster (1999), o habitus desempenha um papel primordial na análise de atitudes subjetivas, bem como na incorporação dos saberes produzidos ao longo da trajetória profissional e pessoal dos professores.

Atualmente, percebemos um direcionamento na formação de professores para a profissionalização do trabalho docente. Assim, "o profissional de ensino deverá ser formado sob a égide de saberes e competências, reagrupados em uma base de conhecimentos tirados da análise da prática pedagógica" (THERRIEN; LOIOLA, 2001). Esse processo formativo é contínuo,
MIZUKAMI (2002) defende que começa antes da formação inicial, pelas experiências anteriores com familiares e professores que fizeram parte da vida escolar. Fundamenta-se na formação inicial, nos cursos de licenciaturas e desenvolve-se ao longo do exercício da carreira, em ambiente escolar.

A partir dessas observações, a escola deixa de ser o lugar apenas para a reprodução de conteúdos curriculares, ou de aplicação de teorias, e avança no sentido de configurar-se como um centro de aprendizagem para os professores, bem como um espaço de produção de conhecimento e de desenvolvimento de práticas inovadores. Além de leva-los a refletir e a sistematizar as experiências, as dificuldades, as inovações e as novas necessidades apresentadas por seus alunos e pelas realidades sociais.

Dentre essas novas realidades, figura o uso das tecnologias no ambiente escolar, exigindo cada vez mais o desenvolvimento acentuado de competências e habilidades, possibilitando ao processo de ensino aprendizagem incrementos para a formação dos educadores e, também, dos educandos. Deve ser levado em consideração não apenas a aquisição de habilidades para o uso das ferramentas tecnológicas, mas também a interação entre os sujeitos envolvidos no processo de ensinoaprendizagem, bem como a análise e a criação de materiais didáticos, e ainda, as reformulações de estratégias de uso dessa tecnologia com os alunos.

Evidencia-se que o espaço imediato de reflexão para o professor é a sala de aula. A partir desse espaço, o docente reinventa sua prática, ressignifica os conteúdos e reflete acerca dos efeitos de suas ações no aprendizado de seus alunos. No entanto, comumente os cursos de formação docente atribuem um papel secundário à sala de aula e desconsideram o aluno como sujeito ativo do processo de aprendizagem, desvalorizando sua contribuição para a o processo formativo do professor.

Pelo que foi exposto, julgamos mais coerente e com maior possibilidade de sucesso ações, cursos ou eventos de formação de professores que fomentem uma postura docente de constante reavaliação de métodos, de conteúdos, de objetivos, enfim, de tudo que compõe o saber-fazer docente, buscando integrar conteúdos acadêmicos às experiências de sala de aula. Tendo ainda o desafio de adequar tudo isso à realidade em transformação, sem se esquecer de captar as contribuições que os alunos vierem a dar ao processo de formação. Com essa atitude, o professor torna-se um pensador autoreflexivo, capaz de avaliar sua prática, além de acompanhar a evolução do conhecimento e as necessidades da sociedade contemporânea. 
Diante da onda tecnológica e de informação que inunda a sociedade atual, as influências sobre o processo de ensino e aprendizagem é um fato inquestionável. E isso implica em mudanças de paradigmas educacionais e institucionais, exigindo dos professores e alunos novas competências e habilidades para o uso dessas tecnologias. Alguns docentes ainda demonstram uma dificuldade em utilizar tais tecnologias, mas todos concordam sobre a presença dela cada vez mais constante no cotidiano escolar.

Uma proposta de utilização de um AVA é, ao mesmo tempo, um desafio e uma oportunidade para os professores. Além de uma formação voltada para o uso dessa tecnologia ser uma resposta a um déficit na formação do professor durante seu curso de licenciatura.

\subsection{Ambiente Virtual de Aprendizagem: tecnologia em sala}

Para VAVASSORI e RAABE (2003), AVA são "sistemas computacionais disponíveis na internet, destinados ao suporte de atividades mediadas pelas tecnologias da informação e comunicação". De maneira mais ampla, adotamos a concepção de AVA como sendo "ambientes computacionais" voltados para o ensino, com a possibilidade de reunir diversos tipos de mídias em um mesmo espaço educacional, promovendo um considerável incremento no processo de ensino-aprendizagem. Ressaltamos a interação, a socialização, a distribuição de materiais on-line, a integralização de diferentes mídias e o apoio ao processo de ensino-aprendizagem dos sujeitos envolvidos no uso dos AVA como principais aspectos desses ambientes.

Dillenbourg, Schneider e Synteta (2002, p.6), destacam a característica de interação como sendo inerente ao AVA, uma vez que, segundo eles, no AVA “os alunos não estão restritos a consultar informações na rede, mas se tornam produtores de informação, eles participam do jogo".

Ainda a respeito da interação, Cole e Foster (2007) afirmam que "Discussões on-line oferecem a oportunidade para muitos alunos se expressarem em formas que não conseguiriam nas aulas regulares. Muitos alunos relutam para falar em sala de aula devido à timidez, incerteza ou questões linguísticas" (COLE; FOSTER 2007, p. 3).

No entanto, iniciativas de aprendizagem em AVA, ou em outros ambientes computacionais educacionais, necessitam de uma proposta de sequências didáticas de ensino que potencialize o processo de ensinoaprendizagem ao qual ele se destina, possibilitando explorar os recursos tecnológicos de maneira mais efici- ente. Para Rocha (2013, p. 99), é de grande relevância que o ambiente virtual utilizado em sala de aula possua uma proposta metodológica "que oriente a prática docente, contribuindo para a formação continuada dos professores e para o seu protagonismo profissional".

\section{METODOLOGIA E MÉTODOS}

A pesquisa realizada foi de caráter qualitativo, do tipo pesquisa-ação, tendo em vista que os sujeitos da pesquisa estariam participando ativamente e a aprendizagem de novas habilidades pelos professores, levaria a agir de forma diferente e melhor em sala de aula para o ensino da leitura. De acordo com Oliveira e Oliveira (1981, p 19), a pesquisa-ação se constitui de ação educativa e promove "(...) o conhecimento da consciência e também a capacidade de iniciativa transformadora dos grupos com quem se trabalha". Ainda sobre a pesquisaação, Gamboa (1982, p 36) destaca o fato de que ela “(...) busca superar, essencialmente, a separação entre conhecimento e ação, buscando realizar a prática de conhecer para atuar".

\subsection{A escolha dos participantes e a aplicação dos questionários}

Participaram da pesquisa 12 professores distribuídos em três escolas. Ao escolher as escolas participantes, considerou-se três critérios: (i) ser da rede estadual de ensino, justificado pelo fato de o pesquisador ser professor dessa rede e ter uma compreensão de sua estrutura, de suas necessidades e limitações; (ii) ser de bairros distintos, buscando desenvolver a pesquisa em diferentes contextos sociais, perspectivas profissionais e educacionais; e (iii) possuir realidades tecnológicas diversas, consciente de que há escolas incluídas no "Cinturão Digital", outras que possuem internet de empresas particulares contratadas pelo governo estadual ou com financiamento próprio de rede. As escolas escolhidas possuem o perfil descrito na Tabela 1 .

A escolha das séries e dos professores participantes da pesquisa ficou a critério das escolas, em respeito à autonomia da gestão escolar. O conhecimento em informática, ou em uso das mídias digitais, não foi o critério da indicação, mas sim o envolvimento nas atividades da escola e a vontade de contribuir com o projeto. Categorizando-se os professores participantes em professor executor e professor substituto.

$\mathrm{O}$ professor executor assumiu o compromisso de utilizar o ambiente com, pelo menos, uma turma durante quatro semanas e seguindo toda a proposta metodológica. O professor substituto poderia ou não ca- 
Tabela 1: Resumo Descritivo das Escolas Participantes

\begin{tabular}{|c|c|c|c|}
\hline Escola & $\mathrm{A}$ & $\mathrm{B}$ & $\mathrm{C}$ \\
\hline Localização & $\begin{array}{l}\text { Bairro nobre } \\
\text { residencial de Fortaleza }\end{array}$ & $\begin{array}{l}\text { Periferia geográfica } \\
\text { e social de Fortaleza }\end{array}$ & $\begin{array}{l}\text { Região central } \\
\text { de Fortaleza }\end{array}$ \\
\hline Alunos & 523 & 1087 & 1251 \\
\hline $\begin{array}{l}\text { Séries } \\
\text { ofertadas }\end{array}$ & $\begin{array}{l}\text { Ensino Médio } \\
\text { Profissional }\end{array}$ & $\begin{array}{l}\text { do } 6^{\circ} \text { ano do Ensino } \\
\text { Fundamental ao } 3^{\circ} \\
\text { ano do Ensino Médio }\end{array}$ & $\begin{array}{l}\text { do } 5^{\circ} \text { ano do } \\
\text { Ensino Fundamental } \\
\text { ao } 3^{\circ} \text { ano do } \\
\text { Ensino } \\
\text { Médio }\end{array}$ \\
\hline Laboratórios & $\begin{array}{l}03 \text { (sem uso de } \\
\text { proxy) }\end{array}$ & $\begin{array}{l}02 \text { fixos e } \\
01 \text { "móvel" } \\
\text { (com uso de proxy) }\end{array}$ & $\begin{array}{l}02 \text { (com uso de proxy } \\
\text { e de servidor local) }\end{array}$ \\
\hline $\begin{array}{l}\text { Máquinas que } \\
\text { utilizam a rede }\end{array}$ & 58 computadores & $\begin{array}{l}51 \text { computadores } \\
\text { e } 40 \text { notebook }\end{array}$ & 67 computadores \\
\hline $\begin{array}{l}\text { Velocidade de } \\
\text { banda larga }\end{array}$ & $\begin{array}{l}2 \text { Mbps (1 Mbps } \\
\text { para os laboratórios } \\
\text { e } 1 \mathrm{Mbps} \text { para o } \\
\text { setor administrativo e professores) }\end{array}$ & $\begin{array}{l}2 \text { Mbps } \\
\text { (dividido } \\
\text { entre dois } \\
\text { pavimentos da } \\
\text { escola) }\end{array}$ & $\begin{array}{l}2 \text { Mbps (com } \\
\text { dificuldades de } \\
\text { uso da rede) }\end{array}$ \\
\hline
\end{tabular}

Fonte: Dados da Pesquisa

dastrar uma turma, mas deveria acompanhar todas as atividades desenvolvidas pelos colegas e participar dos momentos de formação e de construção da pesquisa. Buscou-se um mínimo de dois professores por escola, sendo o professor executor da área de Língua Portuguesa. Duas das escolas solicitaram que fosse permitida a participação de um número maior de professores executores e substitutos, resultando na distribuição descrita na Tabela 2

Tabela 2: Distribuição de Professores Participantes por Escola

\begin{tabular}{|c|c|c|}
\hline $\begin{array}{c}\text { Escola } \\
\text { Participante }\end{array}$ & $\begin{array}{l}\text { Professor } \\
\text { Executor }\end{array}$ & $\begin{array}{l}\text { Professor } \\
\text { Substituto }\end{array}$ \\
\hline Escola A & $\begin{array}{l}\text { 01 de Língua } \\
\text { Portuguesa }\end{array}$ & 01 de Geografia \\
\hline Escola B & $\begin{array}{l}\text { 01 de Língua } \\
\text { Portuguesa } \\
01 \text { de Língua } \\
\text { Espanhola }\end{array}$ & $\begin{array}{l}\text { 03 de Língua } \\
\text { Portuguesa } \\
01 \text { regente do } \\
\text { LEI } \\
01 \text { de Língua } \\
\text { Inglesa }\end{array}$ \\
\hline Escola C & $\begin{array}{l}\text { 01 de Língua } \\
\text { Portuguesa }\end{array}$ & $\begin{array}{l}\text { 01 de Língua } \\
\text { Portuguesa } \\
01 \text { de Biologia }\end{array}$ \\
\hline
\end{tabular}

A utilização do ambiente com os sujeitos da pesquisa, professores e alunos, ocorreu nas escolas ao longo de três meses. Foram realizados no primeiro mês os encontros de formação apenas com professores, tanto presenciais como a distância. Nos dois meses seguintes, os encontros ocorreram com professores e suas turmas, assistidos pelo pesquisador, utilizando o AVA no ambiente escolar e fora dele (em casa, na casa de parentes ou de amigos, em lan house etc).

Ao fim do período de utilização do "Afiando Palavras" por alunos e professores, os usuários foram convidados a responder um questionário, levando-os a refletir acerca da formação, da proposta metodológica e dos recursos do site. O formulário pôde ser preenchido de duas maneiras, ficando a cargo do professor a decisão: online, com um caminho na página inicial do "Afiando Palavras"; ou impresso, respondido em sala de aula.

O questionário apresentava questões objetivas e questões subjetivas, sendo as alternativas das objetivas: 1 - discordo fortemente; 2 - discordo; 3 - prefiro não opinar; 4 - concordo; e 5 - concordo fortemente. Após compilação das respostas e cálculo das médias, percebeu-se que $81,4 \%$ dos usuários concordam que a proposta pedagógica do "Afiando Palavras" é adequada para o desenvolvimento da leitura e pertinente para a aprendizagem.

As questões subjetivas que levaram os usuários a avaliar os aspectos pedagógicos e a própria prática docente, mediante o uso do ambiente foram: "3.1.12. Em sua opinião, indique os maiores benefícios do uso do 
"Afiando Palavras" para sua aprendizagem."; "3.1.13. Qual(is) a(s) dificuldades que você teve em relação à metodologia?"; "3.1.14. Você gostaria de continuar a utilizar o ambiente nas aulas?"

$\mathrm{Na}$ segunda parte do questionário, foram coletadas informações acerca dos aspectos estruturais e técnicos do ambiente a partir das respostas dos usuários. Totalizando trinta questões, vinte e nove questões no formato objetivo e uma no subjetivo, ela buscou perceber a pertinência e as dificuldades no uso da plataforma "Afiando Palavras".

\subsection{A sequência didática e a estruturação do "Afi- ando Palavras"}

Filho (2004) destaca que “(...) a leitura não é dada pelo próprio texto, todavia produzida num processo de interação que inclui o leitor, o texto e seu autor, em determinadas circunstâncias”. Assim, o que deve ser ensinado aos alunos segue nessa perspectiva, ou seja, desenvolver nos educandos a competência para construir tal sentido ao ler, tornando-o um leitor competente e capaz de compreender o que fora lido, e não apenas um mero decodificador de textos.

Nesse sentido, criou-se um percurso para o ensino da leitura com três momentos: $i$. motivação, no qual se desperta a curiosidade por meio da elaboração de um questionamento que se transforme em um ponto de partida para a leitura e que não pode ser óbvio, pois nem alimentaria a curiosidade do aluno, nem faria da leitura do texto uma necessidade para responder à pergunta; ii. ampliando a leitura, com atividades de: a) compreensão textual, ou seja, um levantamento dos fatos e das situações mais importantes presentes na superfície do texto, e b) interpretação textual, pelas quais o aluno tenta relacionar o texto com o cotidiano e com outros textos que ele já leu, expondo sua opinião, ou comentando sobre fatos vivenciados por ele, além de propor possíveis soluções para as situações tratadas no texto; iii. descontração, finaliza-se a leitura com o prazer proporcionado por uma atividade lúdica a partir do texto (bate-papo virtual entre os colegas de turma sobre temas presentes no texto lido, construção de um diário em vídeo etc), levando o aluno a ter desejo de ler cada vez mais.

Em maio de 2013 foram construídos a estrutura, as funcionalidades e os módulos de instalação do AVA "Afiando Palavras" de acordo com a proposta metodológica de sequências didáticas para o desenvolvimento da leitura em ambiente escolar, idealizada a partir dos estudos de Filho (2004). Esse ambiente está hospedado com o endereço www.afiandopalavras.com em domínio próprio e com endereço fixo de IP.

Como base para programação, utiliza-se a versão 2.2.9+ do Moodle. A Customização do ambiente e a seleção dos recursos pertinentes à proposta metodológica do "Afiando Palavras". Também foi realizada a instalação do pacote de plugin de gravação de áudio NanoGong Activity, e a inclusão dessa funcionalidade na barra do editor HTML do ambiente. Por fim, buscou-se criar uma estrutura simples e de fácil administração, representado na Figura 01, que tivesse objetivismo e clareza para criar as funcionalidades do ambiente, minimizando a dificuldade de navegação.

Figura 1: Mapa conceitual do AVA

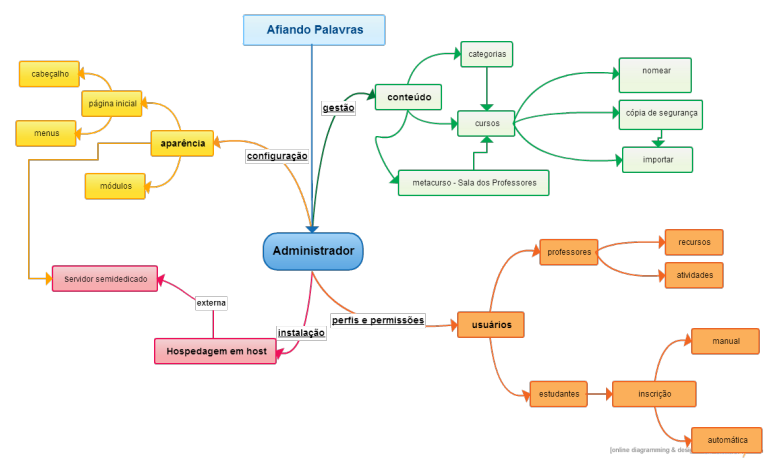

Fonte: Os autores

Levando-se em consideração as necessidades da proposta metodológica, foram selecionados "recursos" e "atividades" para permanecerem ativos no ambiente, buscando simplificar e facilitar o acesso e o uso para os inscritos na plataforma. Sendo que "recursos" são os materiais disponibilizados pelo professor para o aluno ler, não havendo cobrança de um retorno do aluno. Por outro lado, as atividades são "objetos" disponibilizados pelo professor e que, necessariamente, funcionam como um retorno dos alunos.

Criou-se apenas uma "Categoria de curso". Nessa categoria, geram-se os cursos em dois formatos: Sala dos Professores, que reúne todos os professores com cadastro no "Afiando Palavras", subdividida em seis seções; e a Sala de Escola, em que os professores desenvolvem suas atividades com os alunos.

Faz-se presente na primeira seção da "Sala dos Professores" as orientações técnicas para o uso do Moodle, orientações sobre as sequências didáticas, um fórum permanente e um chat com horários agendados. $\mathrm{Na}$ segunda seção, há uma explanação minuciosa de cada uma das três fases que compõem as sequências didáticas, com sugestão de questões para serem utilizadas em suas turmas. A terceira seção apresenta exemplos 
de aulas já montadas no ambiente, para que o professor possa replicar ou se inspirar para a criação de outras. É na quarta seção onde ficam arquivados, em linguagem JQuery $]^{1}$, slides de diversos gêneros textuais, com a definição do gênero em estudo, as características desse gênero, exemplos de textos escritos e exemplos do gênero abordado em uma mídia. A quinta seção funciona como uma biblioteca de diversos autores, divididos por gênero textual. E, finalmente, a sexta seção com links interessantes que também tem, assim como a quinta, uma construção colaborativa.

A construção de uma nova seção poderá ser solicitada pelos professores ao administrador do site. Após a análise do pedido, ela poderá ser criada. Em caso de indeferimento, o administrador do site informa ao solicitante da seção o motivo pelo qual não foi aprovada a nova seção.

\section{RESULTADOS E DISCUSSÃO}

\subsection{Execução das oficinas}

O início do trabalho com os professores se deu com a revisão bibliográfica, referente ao ensino da leitura, e com o entendimento do processo histórico da construção do leitor no Brasil. Daí, buscou-se construir uma concepção de leitura, de leitor e do ensino da leitura. Depois, idealizou-se uma proposta metodológica com sequências didáticas para o desenvolvimento da leitura na escola, somando pontos já destacados por importantes estudiosos da área da linguagem e da linguística, com reflexões sobre a prática escolar. E finalmente, incorporou-se essa concepção a um ambiente virtual de aprendizagem que funcionasse como uma extensão da sala de aula convencional, permitindo ao professor desenvolver seu protagonismo profissional.

Após a escolha dos professores e das turmas que participariam da pesquisa, deu-se início às oficinas de formação. Esse acompanhamento ocorreu principalmente de duas formas: presencial, com visitas semanais à escola e reuniões com os professores envolvidos na pesquisa; à distância, utilizando o próprio ambiente através de chats semanais, fórum permanente, e-mail, vídeo-aulas e por telefone. Para a organização do trabalho da pesquisa, ao fim de cada semana de oficina, havia uma síntese dos avanços e das dificuldades encontrados.

Foram criadas seis salas virtuais: duas para a escola $A$ - uma para o professor executor e outra para o professor substituto; quatro para a escola $B$ - duas para os

\footnotetext{
${ }^{1}$ jQuery é uma biblioteca JavaScript cross-browser desenvolvida para simplificar os scripts client side que interagem com o HTML
}

professores executores e duas para os professores substitutos; e duas para a escola $C$ - uma para o professor executor e uma para o professor substituto.

Quanto ao uso do ambiente pelos alunos, de modo geral, essa ação seguiu os mesmos passos em todas as escolas: os alunos, o professor da disciplina e o pesquisador foram ao laboratório de informática; realizou-se a inscrição dos alunos como usuários do site; depois houve a inscrição na sala de aula virtual do professor; seguida pela explicação sobre características e funcionalidades do ambiente. Porém, em algumas turmas, por impossibilidades técnicas ou de horários, o processo de inscrição se deu de maneira mais autônoma e independente da presença do pesquisador.

Obteve-se a utilização do ambiente "Afiando Palavras" com as turmas participantes em dois tipos de ações: aulas completamente desenvolvidas em espaço físico escolar - atividades desenvolvidas no LEI da escola; aulas desenvolvidas parcialmente em espaço físico escolar - atividades iniciadas na escola, sendo complementadas ou finalizadas no "Afiando Palavras", fosse em casa ou em outro local.

Após o período das atividades, foram aplicados questionários a alunos e professores, cuja análise evidenciou o significado do processo de formação para os sujeitos.

De maneira geral, as respostas dos sujeitos são bem semelhantes, principalmente entre os alunos. Na maioria das vezes, citam o benefício de ler mais claramente, ou de entender melhor os textos, e compreender o que o professor pergunta nas questões das provas. Por sua vez, os professores demonstraram o quão a proposta pode se adequar às principais necessidades da turma e ao enfoque das disciplinas com as quais se dará a utilização do "Afiando Palavras".

Levando-se em consideração os estudos de Campos e Campos (2001) e a proposta de () CHUA e DYSON (2004), as perguntas presentes no questionário aplicado acerca do "Afiando Palavras" buscaram averiguar: (i) adequação e pertinência da proposta pedagógica do site - observando a contribuição para o ensino da leitura e para a prática docente; (ii) usabilidade da plataforma - considerando o grau de dificuldade de uso com alunos da Educação Básica; e (iii) satisfação dos usuários - percebendo o interesse de utilizar o ambiente.

\subsection{As respostas dos usuários}

A primeira parte das perguntas caracteriza o acesso ao computador e à internet pelos usuários. Na segunda, observou-se a adequação e pertinência da proposta pedagógica do ambiente. A terceira parte referia-se a as- 
pectos técnicos do ambiente e das facilidades de uso. Se considerarmos a segunda e a terceira partes juntas, teremos um panorama da satisfação com relação ao ambiente.

\subsubsection{Quanto à adequação e à pertinência da pro- posta pedagógica}

Essa parte do questionário possuía onze questões objetivas e três questões subjetivas, tendo como alternativas das objetivas: 1 - discordo fortemente; 2 - discordo; 3 - prefiro não opinar; 4 - concordo; e 5 - concordo fortemente. Após compilação das respostas e cálculo das médias, percebeu-se que $81,4 \%$ dos usuários concordam que a proposta pedagógica do "Afiando Palavras" é adequada para o desenvolvimento da leitura e pertinente para a aprendizagem, situação demonstrada pelo Gráfico 1

Gráfico 1: Mapa conceitual do AVA

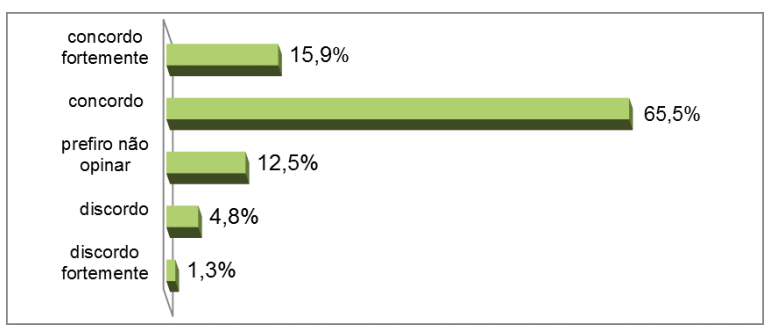

Fonte: Dados da pesquisa

Após as onze questões objetivas, há ainda três questões subjetivas sobre os aspectos pedagógicos da plataforma: "12. Em sua opinião, indique os maiores benefícios do uso do "Afiando Palavras" para sua aprendizagem.”; "13. Qual(is) a(s) dificuldades que você teve em relação à metodologia?"; "14. Você gostaria de continuar a utilizar o ambiente nas aulas?"

a) 12. Em sua opinião, indique os maiores benefícios do uso do "Afiando Palavras" para sua aprendizagem.

As ferramentas incrementam muito o ensino de língua estrangeira. (resposta de um professor da escola A)

Os alunos se envolveram nas atividades e ficaram curiosos para usar o ambiente. Pude colocar textos na sala do site que eu não teria como entregar para todos os alunos em xérox. (resposta de um professor da escola B).

Os nossos jovens gostam de tudo que envolve tecnologia (...), por esse motivo, o desejo de ler foi potencializado pela metodologia, auxiliando $o$ professor em sala. (resposta de um professor da escola C).

b) 13. Qual(is) a(s) dificuldades que você teve em relação à metodologia?

Apesar de ser professor de português, é uma forma bem prática de ensinar a leitura. No início parece meio mecânico, mas depois podemos perceber que a metodologia é bem flexível e vai se adequando bem ao que deve ser trabalhado. (resposta de um professor da escola A)

Gostei de ter algo que me ajuda a montar as aulas. Não é obrigado a fazer igual ao que está descrito na proposta, nós escolhemos as ações e podemos modificar de acordo com a necessidade, sem perder as orientações do site. O professor não substitui, ele agrega oque é bom e usa. (resposta de um professor da escola B)

Sim, pois sou de uma disciplina que não é comumente trabalhada a leitura. Mas depois entendi a proposta e contribuiu para que eu me aperfeiçoasse. (resposta de um professor da escola $\mathrm{C}$ )

c) c) 14. Você gostaria de continuar a utilizar o ambiente nas aulas?

Seria de grande ajuda sim, inclusive a escola está estudando como fazer isso, ou criar um ambiente similar e utilizar, mediante a autorização do pesquisador, as mesmas estratégias de ensino. (resposta de um professor da escola A)

Com certeza, mas é uma pena que agora vou ser coordenadora. Tem como a gente criar um AVA só para professores e gestão? Ou ainda um AVA para professores e pais de alunos? (resposta de um professor da escola B)

Com certeza, embora minha participação não tenha sido tão ativa como eu esperava, esse ambiente deu-me a luz que eu precisava para melhorar minhas aulas. (resposta de um professor da escola C)

\subsection{Comentários dos professores}

Ao longo das oficinas com os usuários, eles teceram constantes comentários sobre o ambiente e sobre a proposta metodológica com sequências didáticas. Contudo alguns pontos mais técnico-pedagógicos, observados pelos professores, merecem uma referência à parte. Inicialmente destacamos que, na opinião de todos os 
professores, o "Afiando Palavras" permite uma utilização diferenciada, de acordo com a especificidade de estilos cognitivos e de aprendizagem diferenciados.

Tendo em vista que os jovens são muito ligados às redes sociais, usar um ambiente virtual para ministrar atividades diversifica minha didática e estimula os alunos a participarem mais. (resposta de professor da escola B)

Sim, pois sou de uma disciplina que não é comumente trabalhada a leitura. Mas depois entendi a proposta e contribuiu para que eu me aperfeiçoasse. (resposta de professor da escola C)

Também acreditam que o ambiente seja adequado para uma utilização curricular de natureza transdisciplinar, promovendo a aprendizagem e avaliando de diferentes formas a evolução dos alunos, uma vez que o ambiente inclui um sistema de registro de notas que poderá ser utilizado a qualquer momento pelo professor.

Podemos avaliar os trabalhos de muitas maneiras e utilizar no ambiente ainda permite que se use a escala de notas. (resposta de professor da escola B)

Acho interessante a possibilidade de avaliar a leitura dos alunos em casa, ouvir a leitura de um por um e sem ter o transtorno que a sala pode dar. (resposta de professor da escola A)

Por fim, os docentes observaram que, mesmo não tendo sido objeto de nossa pesquisa, o rendimento dos alunos deu indícios de uma melhora. Essa primeira impressão foi bastante promissora e motivadora para todos.

Ajudou os alunos a identificar tópicos importantes nos textos. Isso, possibilitou que eles aprendessem mais, mesmo em outras disciplinas. (resposta de professor da escola A)

(...) Porque os alunos entenderam melhor e a aprenderam mais sobre os conteúdos. (resposta de professor da escola B)

\section{CONSIDERAÇÕES FINAIS}

No início de 2013, foi realizada uma pesquisa junto a escolas públicas da rede estadual de educação do Ceará, utilizando um Ambiente Virtual de Aprendizagem com proposta pedagógica própria. Participaram dessa pesquisa alunos e professores, sendo proposto pelo ambiente e por suas sequências didáticas a motivação dos alunos para a leitura, possibilitando a compreensão e a interpretação do texto e, finalmente, desenvolvendo atividades lúdicas relacionadas à leitura. Paralelamente a isso, fomentou-se a ação auto-reflexiva dos docentes sobre sua prática pedagógica, a partir das atividades desenvolvidas com os alunos no ambiente virtual.

Evidenciamos a necessidade de um plano de formação continuada a partir da realidade das escolas e, preferencialmente, realizado em interação com o próprio contexto de sala de aula. As críticas por parte dos professores a respeito das formações ofertadas pelas Secretarias de Educação e pelo Ministério da Educação (MEC) recaem, principalmente, sobre as temáticas abordadas e sobre o distanciamento do cotidiano escolar.

Ciente dessa realidade, o Governo Federal dá início a um grande programa de formação para professores que ministram aula no ensino médio em escolas públicas de todo o Brasil - o "Pacto pelo Ensino Médio" com início em 2014. No entanto, esse novo programa de formação em exercício para professores do ensino médio não pode cometer os mesmos erros de outros cursos de formação: minimizar a abordagem dos problemas e aspectos da realidade das escolas, em detrimento de teorias concebidas distantes do ambiente escolar e; sobrecarregar o professor com aprofundamento de conteúdos acadêmicos.

Estudos e pesquisas que apenas versam sobre a escola, ou sobre o como ensinar, sobre como realizar uma aula melhor, abordando uma realidade proposta ou imaginada, gera uma desmotivação e pouca credibilidade entre os professores, por não se reconhecerem nesses cenários "ideais para análise".

Por essa constatação buscamos, no segundo momento das oficinas desenvolvidas em nossa pesquisa, já com a participação dos alunos, estruturar e executar as ações no ambiente a partir de situações reais da sala de aula, motivadas por uma necessidade prática. Depois, era realizada proposição de uma ou mais respostas, uma reflexão sobre o que mais era mais adequado de realizar e, finalmente, a aplicação. Sendo garantido ao professor modificar, refazer, estender ou qualquer alteração.

Com a continuidade das oficinas, professores e alunos descobriram as possibilidades do sistema e da sequência didática, gerando uma maior identificação entre eles, promovendo uma significativa interação pela proximidade dos papéis, partilhando dúvidas e descobertas. Esse fato levou os professores à reflexão sobre 
autoridade, respeito e aprendizagem em cooperação.

Evidenciou-se outro benefício de grande relevância para a pesquisa: ao utilizar o "Afiando Palavras", os professores não se propuseram apenas a compreender o sistema e a sequência didática, mas a alterá-los e reconstruí-los ao seu modo, de acordo com suas escolhas e necessidades, mediante uma reflexão sobre quais caminhos tomar e, em muitos momentos, em interações com os alunos. Chama a atenção, o modo como os sujeitos participantes da pesquisa analisaram o desenvolvimento das ações. O processo de ensino-aprendizagem permeou a pesquisa científica, fomentando em todos o papel de corresponsáveis pela pesquisa e pelos avanços das oficinas de formação. Nesse sentido, o professor não só aprendeu por meio de saberes experienciais, como foi o sujeito responsável por pensar sua prática e seus saberes, demonstrando uma postura auto-reflexiva.

Segundo os professores, os principais resultados positivos da pesquisa seriam: os alunos motivados; a orientação do percurso metodológico para o trabalho em sala de aula; e os diversos recursos do site a sua disposição, sendo utilizados de acordo com a criatividade de cada educador, na estruturação das aulas. Nesse sentido, reiteramos a importância de uma proposta metodológica em um AVA que oriente a prática docente, contribuindo para a formação continuada dos professores e para o seu protagonismo profissional.

Pode-se perceber que essa experiência formativa com o "Afiando Palavras" traz uma proposta bem inovadora, pois não objetiva o repasse de conteúdos, ou de proposições de atividades estanques. Também o produto final não se resume ao registro das atividades e tampouco o maior benefício esperado são as notas das provas no final do bimestre. Ao contrário disso, foi discutida uma proposta metodológica flexível, com sequências didáticas que se adequam às decisões do professor, mediante a análise da repercussão junto aos alunos, direcionando os encaminhamentos após uma reflexão sobre o que foi realizado com os alunos e observado graças à interação com a turma. O produto final é a ação reflexiva do professor e do aluno, assim como o real benefício é um processo de ensino-aprendizagem em que tanto docente como discente são protagonistas do saber-fazer.

Ainda há uma resistência em relação a ações formativas de professores em exercício com a participação direta de alunos, parte motivada pelo receio dos impactos na aprendizagem dos discentes, parte por conta de ser impensável compartilhar com alunos as inseguranças, as incertezas e as falhas que venham a ser expostas nesses cursos de formação. Esse medo impossibilita os be- nefícios que uma formação auto-reflexiva com docentes e discentes, interagindo e construindo a aprendizagem venha trazer.

A partir dessa experiência, resta-nos investigar a eficiência de ações formativas para professores que sejam desconexas com o ambiente escolar, distantes das questões pertinentes às salas de aula e sem a interação com os alunos, comparando-as às ações que unam educadores e alunos em prol de um aperfeiçoamento da prática pedagógica dos docentes.

\section{REFERÊNCIAS}

BOURDIEU, J. P.; FOSTER, H. O poder simbólico. Rio de Janeiro: , 1999.

COLE, J.; FOSTER, H. Using Moodle: Teaching with the popular open source course management system. : "O’Reilly Media, Inc.", 2007.

FILHO, J. B. Uma leitura da literatura infantil na escola. Fortaleza: Breves Palavras, 2004.

MIZUKAMI, M. d. G. Formadores de professores, conhecimentos da docência e casos de ensino.

Formação de professores, práticas pedagógicas e escola. São Carlos: Ed. UFSCar, p. 151-174, 2002.

NÓVOA, A. Concepções e práticas de formação contínua de professores. Formação contínua de professores: realidade e perspectivas. Portugal: Universidade de Aveiro, 1991.

PIMENTA, S. G. Didática e formação de professores: percursos e perspectivas no brasil e em portugal. Cadernos de Pesquisa, n. 103, p. 190, 2013.

ROCHA, J. A. "afiando palavras": customização e estruturação de um ava para o ensino da leitura com proposta metodológica própria. 2013.

TARDIF, M. Saberes docentes e formação profissional. : Editora Vozes Limitada, 2012.

THERRIEN, J.; LOIOLA, F. A. Experiência e competência no ensino: pistas de reflexões sobre a natureza do saber-ensinar na perspectiva da ergonomia do trabalho docente. Educação \& Sociedade, SciELO Brasil, v. 22, n. 74, p. 143-160, 2001.

VAVASSORI, F. B.; RAABE, A. L. Organização de atividades de aprendizagem utilizando ambientes virtuais: um estudo de caso. SILVA, Marco (org). Educação online: teorias, práticas, legislação, formação corporativa. São Paulo: Loyola, p. 311-325, 2003. 